\title{
Antihelminthic Agent
}

National Cancer Institute

\section{Source}

National Cancer Institute. Antihelminthic Agent. NCI Thesaurus. Code C250.

A pharmacological agent that can kill or prevent the reproduction of parasitic helminths, including nematodes, flukes and tapeworms. 